\title{
Improved impression cytology techniques for the immunopathological diagnosis of superficial viral infections
}

\author{
M A Thiel, W Bossart, W Bernauer
}

\begin{abstract}
Background-For epidemiological and therapeutic reasons early diagnosis of superficial viral infections is crucial. Conventional microbiological techniques are expensive, time consuming, and not sufficiently sensitive. In this study impression cytology techniques were evaluated to analyse their diagnostic potential in viral infections of the ocular surface.

Method-A Biopore membrane device instead of the original impression cytology technique was used to allow better quality and handling of the specimens. The impressions were processed, using monoclonal antibodies and immunoperoxidase or immunofluorescence techniques to assess the presence of herpes simplex virus, varicella zoster virus, or adenovirus antigens. Ocular surface specimens from healthy individuals $(n=10)$ and from patients with suspected viral surface disease $(n=19)$ were studied. Infected and non-infected cell cultures served as controls.
\end{abstract}

Results-This modified technique of impression cytology allowed the collection of large conjunctival and corneal epithelial cell layers with excellent morphology. Immunocytological staining of these samples provided diagnostic results for all three viruses in patients with viral surface disease.

Conclusions-The use of Biopore membrane devices for the collection of ocular surface epithelia offers new diagnostic possibilities for external eye diseases. Immunopathological methods that are applied directly on these membrane devices can provide virological results within 1-4 hours. This contributes considerably to the clinical management of patients with infectious diseases of the ocular surface.

(Br F Ophthalmol 1997;81:984-988)

Early identification of the causative organism is highly desirable for the management of infectious eye diseases. Because of the epidemio- logical and therapeutic consequences rapid microbial diagnosis would be particularly helpful in herpetic or adenoviral disease of the ocular surface. In these conditions the initial diagnosis still relies mainly on clinical signs, although progress has been made in the development of diagnostic techniques. ${ }^{1-3}$ Culturing is still regarded as the standard for the diagnosis of viral diseases. ${ }^{4}$ Results by this method, however, are available only after several days and depend on viable, infectious material that usually has to be transferred to a specialised laboratory for processing. ${ }^{5}$ Rapid diagnostic tests that allow processing on site and give results within hours, hence avoiding these problems, were developed and evaluated in the 1980s. ${ }^{6-11}$ These tests, based on immunocytological staining of conjunctival scrapings, produced rapid results with good specificity but only moderate sensitivity. ${ }^{12}$ The limited sensitivity was caused probably by the collection technique that bears the risk of losing (or missing) the few infected cells. These tests were therefore never really adopted by ophthalmologists.

Epithelial cells from the conjunctiva and the cornea lose their adhesion to neighbouring cells when they become infected, and this makes them an ideal target for impression cytology. This technique was first reported by Egbert and coworkers in $1977^{13}$ who found that an imprint of the superficial cell layer could be obtained by pressing a cellulose acetate filter on the ocular surface. Modified by several authors, this non-invasive biopsy technique was rapidly adopted and used for histological studies on dry eyes, vitamin deficiencies, ocular cicatricial pemphigoid, but only occasionally for microbiological tests. ${ }^{14-22}$ Despite the theoretical simplicity and diagnostic potential of this method, its advantages have been outweighed by the inconvenience of the technique in use and therefore impression cytology has not yet become a routine diagnostic tool.

In this study a modified impression cytology technique in combination with immunological antigen detection was evaluated to develop a simple, rapid, and reliable test for ocular surface infections caused by herpes simplex 


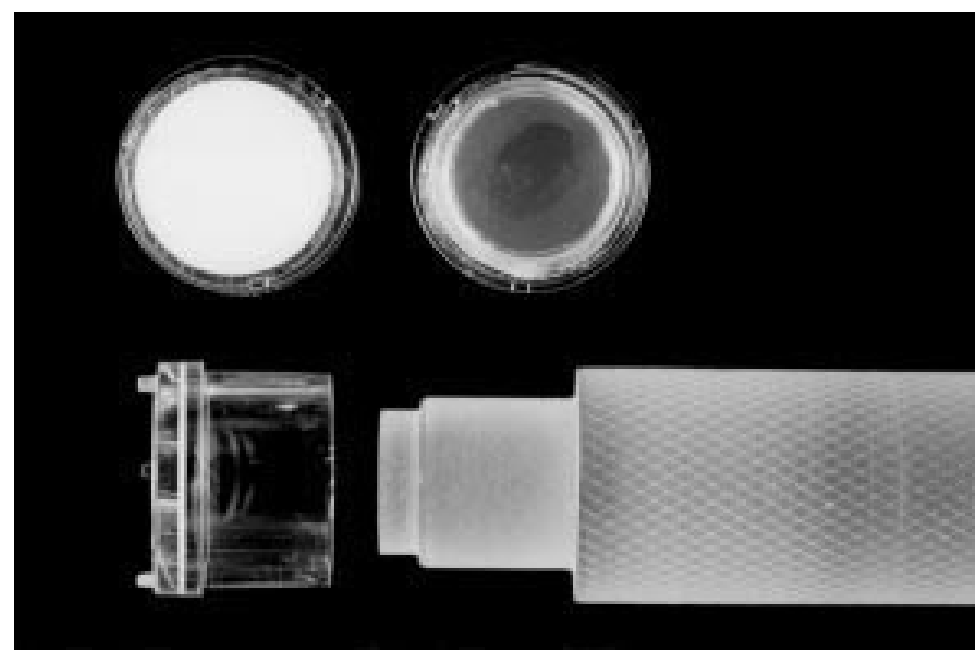

Figure 1 The Biopore membrane device. (Top left) dry membrane (white); (top right) wet transparent membrane; (bottom left) device shown from the side with three small legs that are broken off before impression; (bottom right) this plastic rod is inserted into the device as a handle.

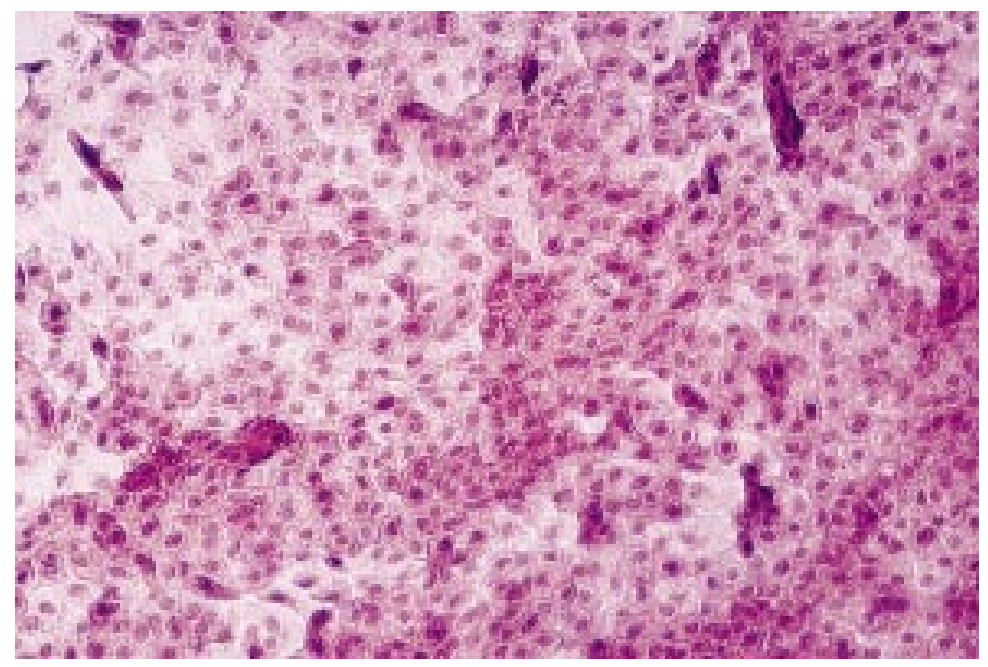

Figure 2 Typical appearance of a conjunctival impression harvested by the Biopore membrane. Large monolayers are seen without mechanical artefacts.

virus (HSV), varicella zoster virus (VZV), and adenovirus.

\section{Method}

PATIENTS

Impression cytology specimens were obtained from healthy volunteers $(n=10)$ and from patients $(n=19)$ with suspected viral surface disease who attended the eye hospital of the University of Zurich. Fourteen patients were clinically diagnosed to suffer from an HSV dendritiform corneal lesion, three showed clinical signs of zoster ophthalmicus with conjunctivitis and/or keratitis, and two were suspected of having an acute adenoviral ocular infection.

SPECIMEN COLLECTION

After topical anaesthesia with oxybuprocaine eyedrops $0.4 \%$ conjunctival and/or corneal cytology impressions were obtained by using a single packed, sterile Biopore membrane (Millicell-CM 0.4 $\mu \mathrm{m}$ PICM 012550, Millipore Corp, Bedford, MA, USA). This membrane is spread out at the end of a short plastic tube (Fig 1) and can be used without additional coating. To avoid ocular trauma, the three legs at the edge of the tube were broken off with a forceps. The tube with the Biopore membrane at its end was gently pressed on the ocular surface for 3-5 seconds. To ensure an optimal contact between the membrane and the ocular surface a small self manufactured plastic rod that was inserted into the tube served as a handle (Fig 1). The membrane device was then removed and stored back in its original package for transport to the laboratory. To increase the number of cells that were harvested, the ocular surface was slightly dried with a cotton swab or by keeping the eye open for some time before impression cytology was performed. The cells were fixed during transport by air drying.

\section{IMMUNOPATHOLOGY}

The immunopathological techniques were evaluated and modified for use with Biopore membranes with the help of positive and negative control samples. For this purpose impressions were taken from infected and noninfected cell cultures (herpes simplex virus type 1, strain McIntyre, grown in vero cells; varicella zoster virus, strain Ellen, and adenovirus type 7 , both viruses grown in human foreskin fibroblasts). The influence of storing was assessed by a series of impressions that were taken from cell cultures and that were stained and examined at different times up to 2 weeks after the cells had been harvested and fixed by air drying. These specimens were stored at room temperature, $4^{\circ} \mathrm{C}$, and at $-20^{\circ} \mathrm{C}$. They showed a similar positive staining pattern during the first week and a diminishing reactivity thereafter. No obvious effect of the storage temperature was noted on the immunopathological staining pattern.

\section{Immunoperoxidase staining}

Prediluted primary antiviral and secondary rabbit or mouse antibodies in combination with a commercial peroxidase antiperoxidase kit were used, following the manufacturer's instructions (prediluted rabbit anti-HSV type I antibody, Dako, Copenhagen, Denmark; mouse anti-VZV antibody, Argène 11-017; mouse anti-adenovirus antibody, Argène 11-020, Varilhes, France; PAP-kit Dako, Copenhagen, Denmark). The staining procedure was performed directly on the Biopore membrane that stayed mounted on the plastic tube. PBS (phosphate buffered saline 0.85\%) was used as bathing solution. Tween 20, 0.05\% (polyoxyethylensorbitan monolaurate P 5188, Sigma St Louis, USA) was added to the PBS to increase the antibody permeability through the cell membrane. The specimens were incubated with primary and secondary antibodies for 20 minutes each. Counterstaining was performed by dipping the membrane device with a forceps directly into a bath with Meyer's haemalum solution for 20 seconds. Light microscopy was used to examine the staining pattern. An intensive red-brown staining was regarded as a positive result. 


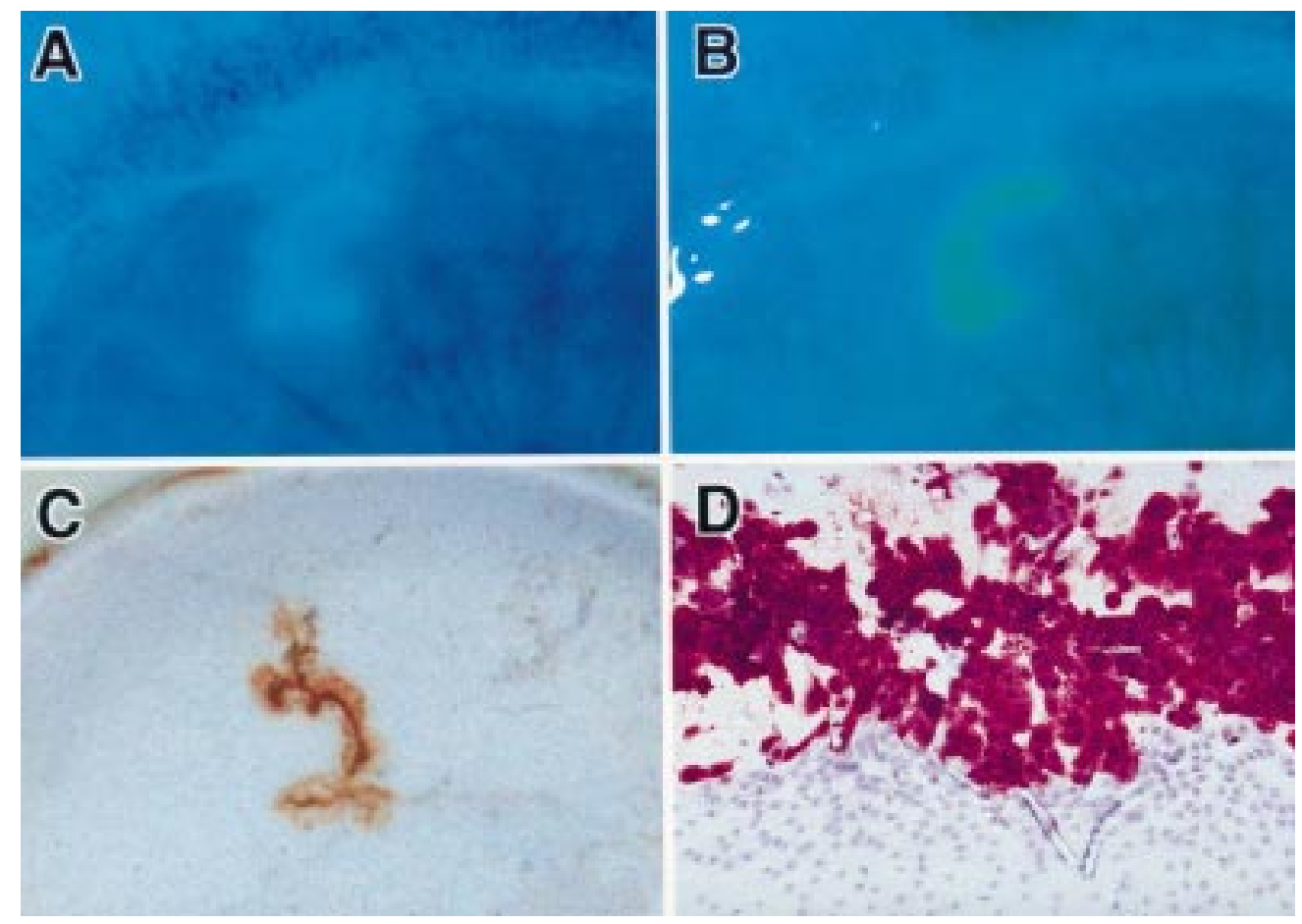

Figure 3 Dendritic corneal lesion. $(A)$ and (B) before and after the impression. Note the well defined debridement of the herpetic lesion; (C) macroscopic aspect after immunohistological staining (PAP); (D) light microscopy reveals HSV antigen positive cells (red-brown) and negative cells (blue) (original magnification $\times 40$ ).

\section{Immunofluorescence}

For immunofluorescence analysis an indirect method using prediluted primary (mouse antiVZV antibody, Argène 11-017, Varilhes, France) and secondary antibodies (FITC labelled goat anti-mouse IgG antibody, Kirkegaard and Perry 02-28-06, Gaithersburg, MD, USA) was followed. Counterstaining was done with Evan's Blue (Sigma 2129, St Louis, MO, USA) mixed to the solution of the secondary antibody. The staining procedure was performed directly on the Biopore membrane. The specimens were incubated with primary and secondary antibodies for 30 minutes each, followed by three washing cycles of 5 minutes each with PBS. The results were assessed under a transmission fluorescence microscope.

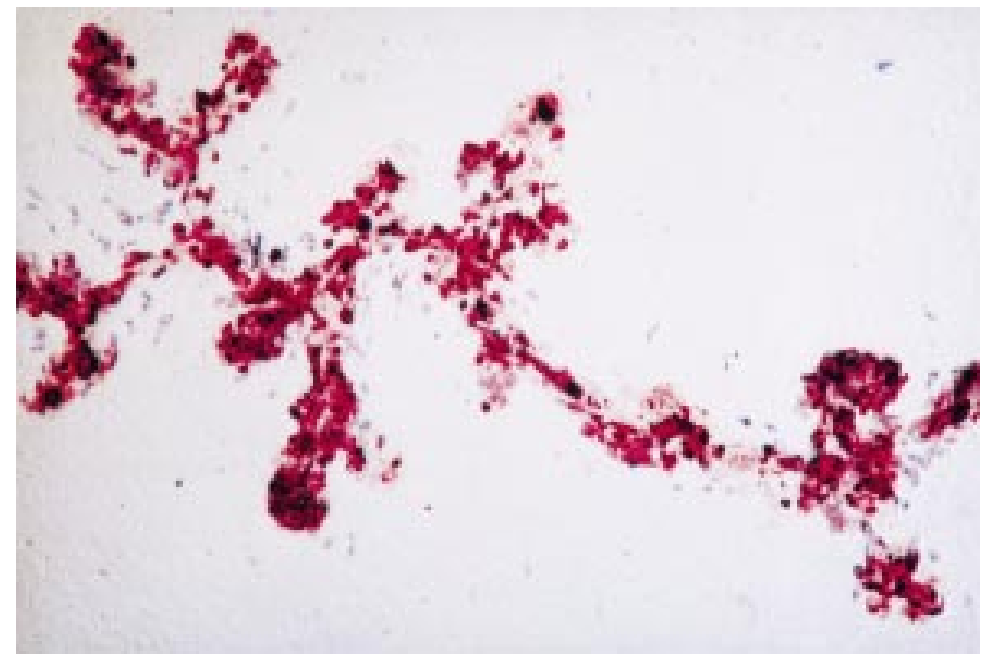

Figure 4 Superficial herpetic keratitis. Impression of a dendritic corneal lesion after immunocytological staining (anti-HSV 1, PAP).
Since the samples were only fixed by air drying they remained potentially infectious and therefore gloves were used throughout the procedures. All the staining and washing solutions were sterilised to avoid contamination.

\section{Viral culturing}

To compare the diagnostic liability of impression cytology in combination with an immunopathological staining technique to viral culturing, all corneal and conjunctival lesions were additionally swabbed with a cotton tipped applicator. The specimens were examined by viral culturing on vero cells and human foreskin fibroblasts. ${ }^{5}$

\section{Results}

SPECIMENS

The impression technique with the integrated, packed membrane and holder device was easy to learn and even inexperienced examiners were able to collect excellent specimens. Usually large areas of mono- to bilayers of conjunctival and single cell layers of corneal epithelial cells were harvested by the Biopore membrane (Fig 2). The cell adhesion to the Biopore membrane after fixation by air drying was stable enough to allow vigorous bathing and rinsing during the staining procedures without losing a significant number of cells. In a wet state the Biopore membrane is fully transparent and allows a detailed cytological examination by light and fluorescence transmission microscopy. But even dry the membrane is transparent enough for cytological examination. 


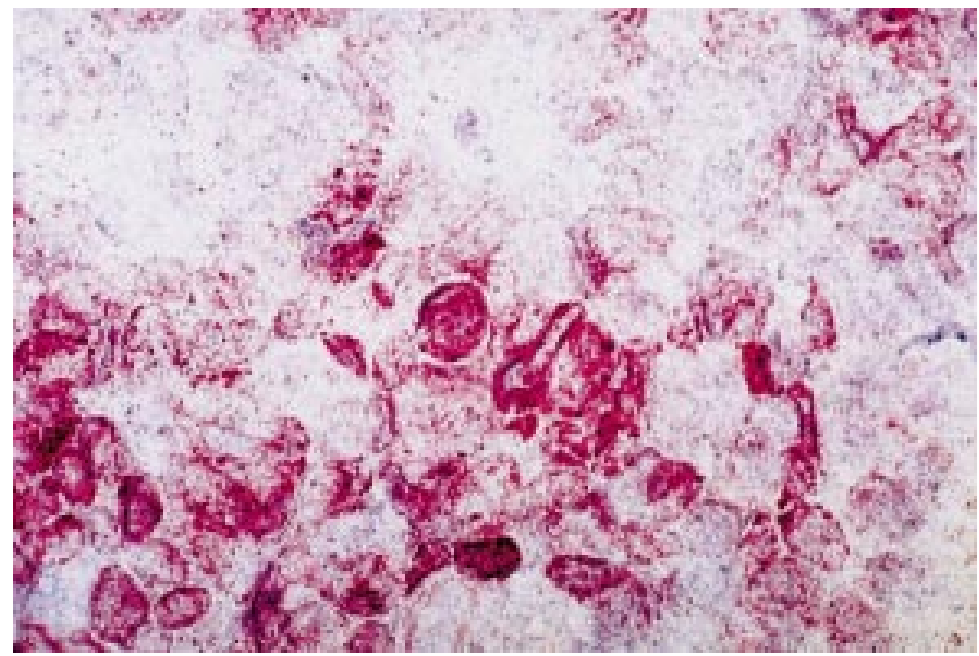

Figure 5 Conjunctival impression in adenoviral disease. Infected cells present with a brown-red PAP reaction after incubation with adenovirus antibody (original magnification $\times 40)$.

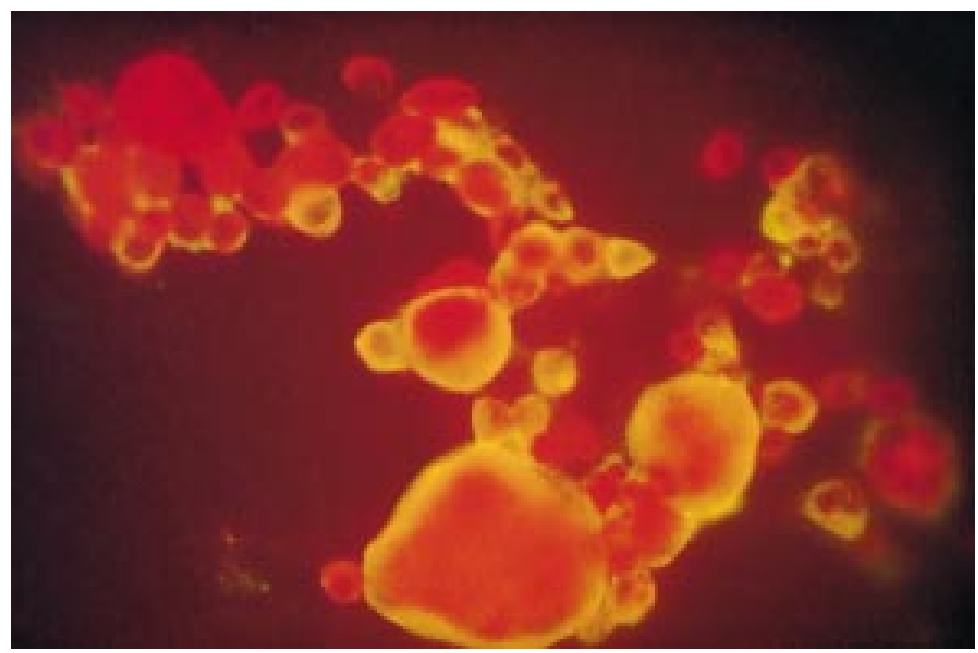

Figure 6 Dendritic lesion with varicella zoster virus. Immunofluorescence staining performed directly on the Biopore membrane shows positive cells with bright yellow fluorescence.

\section{Discussion}

This membrane technique for impression cytology combined with immunopathological examination has major advantages when compared with conventional tests for diagnosis of superficial viral infections. They include the possibility of an immediate specimen's quality assessment and, since there is no need for a transfer to glass slides or media, this quality is maintained throughout the processing. In addition, this test is rapid, easy to perform and, since there is no need for culture media, easy to keep in stock.

Negative results after conventional swabbing or scraping techniques raise the question of whether the pathological cells were actually collected and whether they were correctly transferred from the cotton swabs into the test wells (for culture) or onto the glass slides (for immunocytological staining). ${ }^{62}{ }^{23}$ In contrast, our technique of impression cytology allows the assessment of the sample quality immediately after the impression since the dull membrane surface becomes slightly shiny when covered with cells. When poor cell collection is suspected, the procedure can be repeated several times to ensure that a large number of cells are harvested from the pathological site on the conjunctiva or cornea.

The Biopore membrane as used in this study offers significant advantages over cellulose acetate membranes in conventional impression cytology techniques. The mechanical stability of the device allows application and removal of the membrane in a strictly orthogonal direction to the ocular surface. This prevents mechanical shear artefacts in the collected cell layer. The good adhesion of cells to the Biopore membrane allows harvesting of large layers of cells. This adhesion of the cells is not affected after fixation by air drying and makes immunopathological staining possible without the risk of losing cells. Since the Biopore membrane is fully transparent in its wet state or when treated with immersion oil, transmission microscopy, even with high magnification, can be easily performed. In contrast with the conventional cellulose acetate membrane as used by Nakagawa and others, ${ }^{22}$ the Biopore membrane has a very low background fluorescence. This allows the use of fluoresceinated anti-bodies for the detection of antigens.

So far all our positive results gained by this immunocytological test were confirmed by culturing techniques $4-7$ days later. This indicates a high specificity of the 'immunopathology on Biopore impression' technique. We would expect that this technique has a higher sensitivity than immunocytological analysis of conjunctival swabs or scrapings ${ }^{12}$ since a much larger number of cells can be examined.

Further studies are required to define the diagnostic value of this new approach in the evaluation of ocular viral infections. The authors wish to thank Professor B Gloor who encouraged
this study with his inspiring ideas and the Bruppacher Foundation for financial support. We would also like to thank Mrs R Ganzfried for her assistance with the staining procedures and Ganzfried for her assistance with the staining
M Ber for his help with the photographs.

This work has not previously been presented. Proprietary interest: None. 
1 Yamamoto S, Shimomura Y, Kinoshita S, Nishida K, Yamamoto R, Tano Y. Detection of herpes simplex virus ANA in human tear film by the polyn

2 Hareuveni T, Maurice DM. Short-term reproducibility of impression cytology. Cornea 1994;13:250-2

3 Dumas A, Ancos Ed, Herbort C. Evaluation de la méthode d'amplification de l'ADN (PCR, polymerase chain reaction) pour le diagnostic de l'herpes oculair superficiel. Klin Monatsbl Augenheilkd 1992;200:472-5.

4 Gleaves CA, Hodinka RL, Johnston SLG, Swierkosza EM In: Baron EJ, ed. Cumitech 15A, Laboratory diagnosis of viral infections. Washington DC: American Society for Microbiology, 1994.

5 Lennette EH. In: Laboratory diagnosis of viral infections. New York: Marcel Dekker Inc, 1992.

6 Herbort CP, Perentes E, Matter M, Faggioni R, Pyndiah N. Rapid diagnosis of herpetic infections by immunoperoxiRapid diagnosis of herpetic infections by imm

7 Catalano RA, Webb RM, Smith RS, Duke MA. A modified immunoperoxidase method for rapid diagnosis of herpes immunoperoxidase method for rapid diagnosis of

8 Dunkel EC, Pavan-Langston D, Fitzpatrick K, Cukor G. Dunkel EC, Pavan-Langston D, Fitzpatrick K, Cukor G.
Rapid detection of herpes simplex virus (HSV) antigen in Rapid detection of herpes simplex virus (HSV) antigen

9 Wiley L, Springer D, Kowalski RP, Arffa R, Roat MI, Thoft $\mathrm{RA}$, et al. Rapid diagnostic test for ocular adenovirus. $O p h-$ thalmology 1988;95:431-3.

10 Kowalski RP, Gordon YJ. Comparison of direct rapid tests for detection of adenovirus antigen in routine conjunctival specimens. Ophthalmology 1989;96:1106-9.

11 Kowalski RP, Gordon YJ. Evaluation of immunologic tests for the detection of ocular herpes simplex virus. Ophthalmology 1989:96:1583-6.

12 Wiley LA, Roba LA, Kowalski RP, Romanowski EG, Gordon YJ. A 5-year evaluation of the Adenoclone test for the rapid diagnosis of adenovirus from conjunctival swabs. Cornea 1996;15:363-76.

13 Egbert PR, Lauber S, Maurice DM. A simple conjunctival biopsy. Am f Ophthalmol 1977;84:789-801.

14 Nelson JD. Ocular surface impression using a cellulose acetate filter material. Ocular pemphigoid. Surv Ophthalmol 1982;27:67-9.

15 Nelson JD, Wright JC. Conjunctival goblet cell densities in ocular surface disease. Arch Ophthalmol 1984;102:104951.

16 Tseng SCG. Staging of conjunctival squamous metaplasia by impression cytology. Ophthalmology 1985;92:728-33.

17 Götz ML, Kruse FE, Jäger W. Die Impressionzcytologie der Bindehaut-Eine nichtinvasive Untersuchungsmethode; 1 Technik der Entnahme der Präparate. Fortschr Ophthalmol 1986;83:31-3.

18 Nelson JD. Impression cytology. Cornea 1988;7:71-81.

19 Natadisastra D, Wittpenn J, West K, Muhilal, Sommer A. Impression cytology for detection of vitamin A deficiency. Arch Ophthalmol 1987;92:1224-8.

20 Maskin SL, Heitman KF, Lawton AW, Yee RW. Diagnostic impression cytology for external eye disease. Cornea 1989; 8:270-3.

21 Baudouin C, Haouat N, Brignole F, Bayle J, Gastaud P. Immunopathological findings in conjunctival cells using men. Br f Ophthalmol 1992;76:545-9.

22 Nakagawa H, Uchida Y, Takamura E, Nakagawa Y, Araki H, Watanabe M. Diagnostic impression cytology for herpes simplex keratitis. Fpn f Ophthalmol 1993;37:505-13.

23 Kowalski RP, Gordon YJ, Romanowski EG, Araullo-Cruz T, Kinchington PR. A comparison of enzyme immunoassay and polymerase chain reaction with the clinical examination for diagnosing ocular herpetic disease. Ophthalmology 1993;100:530-3. 